\title{
Polymorphisms in the human serotonin receptor 1B (HTR1B) gene are associated with schizophrenia: a case control study
}

\author{
Xi Xia, Mei Ding, Jin-feng Xuan, Jia-xin Xing, Hao Pang, Bao-jie Wang ${ }^{*}$ (i) and Jun Yao*
}

\begin{abstract}
Background: Schizophrenia is associated with multiple neurotransmitter disorders, including serotonin (5hydroxytryptamine, 5-HT). The neuromodulatory action of serotonin on brain function largely depends on the action of specific subtypes of serotonin receptors. The serotonin receptor 1B (HTR1B) gene has been proposed to play putative roles in the development of multiple emotional and psychiatric disorders.
\end{abstract}

Methods: To study the relationship of HTR1B polymorphisms and schizophrenia, gene information was drawn from a cohort of 310 schizophrenic patients (152 men and 158 women) and 313 healthy controls (153 men and 160 women) of northern Han Chinese descent. The $x 2$ test was used to compare allele and genotype distributions between case and control groups. The haplotype and linkage equilibrium were also assessed in two group comparisons.

Results: We detected 14 SNPs. Male patients were observed to have higher frequencies of the A-allele and AA+AG genotype at rs 1778258 than female patients ( $p=0.012$ and $p=0.015$, respectively). Both the A-allele and AA+AG genotype were associated with schizophrenia risk ( $O R=1.986$ and $O R=2.061$, respectively), although the statistical significance of the genotype was lost after Bonferroni correction. Linkage analysis showed that rs17273700, rs11568817, rs9361234 and rs58138557 polymorphisms exhibit strong linkage disequilibrium (LD). In addition, schizophrenic patients show stronger linkage between 11,568,817 and rs130058 than healthy controls.

Conclusions: HTR1B polymorphisms are associated with schizophrenia in the northern Han Chinese population, which provides an etiological reference for schizophrenia.

Keywords: Schizophrenia, Single-nucleotide polymorphisms (SNPs), Serotonin receptor 1B (HTR1B)

\section{Background}

Schizophrenia is a chronic disabling mental disorder affecting more than 21 million people worldwide, and is characterized by distortions in perception, thinking, emotions, sense of self and behavior. Common experiences include hearing voices and delusions (WHO2016). The etiology of schizophrenia is complicated, and genetic studies have had a guiding influence on schizophrenia research. A genome-wide association study (GWAS) suggested that schizophrenia is a complex polygenetic disease with over $80 \%$ heritability [1]. Numerous studies have focused on the neurotransmitters related to the pathogenesis

\footnotetext{
*Correspondence: wangbj77@163.com; yaojun198717@163.com; 198717@163.com

School of Forensic Medicine, China Medical University, No. 77 Puhe Road, Shenbei New District, Shenyang 110122, China
}

of schizophrenia, including serotonin. Serotonin plays an import role in various brain activities including emotions, pain, assault, learning and memory [2].

The neuromodulatory action of serotonin on brain function largely depends on the actions of serotonin receptors, which comprise at least 14 different classes of subtypes [3]. HTR1B is a G-protein coupled receptor that activates a second messenger cascade to mediate inhibitory neurotransmission and regulate the release of serotonin, dopamine, and acetylcholine in the brain. HTR1B has been suggested to be associated with multiple emotional and psychiatric problems, including attention deficit hyperactivity disorder (ADHD) [4], antisocial behavior [5], aggressive behavior [6], bipolar disorder, anxiety/depression, schizophrenia $[7,8]$ and substance abuse [9]. It is also a common target for

(c) The Author(s). 2018 Open Access This article is distributed under the terms of the Creative Commons Attribution 4.0 International License (http://creativecommons.org/licenses/by/4.0/), which permits unrestricted use, distribution, and 
psychotherapeutic drugs. The HTR1B gene is located on chromosome 6 at position 77,460,848-77,464,022 (GR Ch38.p7). It has been suggested that schizophrenic patients show increased HTR1B mRNA levels in the hippocampus. Simultaneous upregulation of $H T R 1 B$ and downregulation of HTR2A could decrease GABAergic activity, which leads to an increased glutamatergic efferent in the hippocampus [7]. In previous studies, there were inconsistent results on the genetic association between HTR1B gene variations and schizophrenia. For example, rs2143823 is considered to be related to schizophrenia in Croatians [10]. However, there was no correlation between G861C and schizophrenia in Portuguese, German and Brazilian patients [11-13]. The associations between C129T, T371G, T655C, C705T, G861C, A1099G, G1120A and schizophrenia were also negative in mixed populations in the United States [14]. In addition, the HTR $1 B$ haplotype may be implicated in the gender discrepancy of schizophrenia in Spanish populations [15].

As the function of the coding regions has been studied extensively, SNPs located in regulatory regions were taken in to consideration. Prior studies addressing the association between schizophrenia and HTR $1 B$ polymorphisms in the Chinese Han population include only the $5^{\prime}$-untranslated (5'UTR) and coding regions, with little data concerning the $5{ }^{\prime}$-promoter and 3 '-regulatory regions. Therefore, we chose to investigate these regions to improve etiologic knowledge of this disease. Expanding sequences were investigated in our study, including a 2285 bp $5{ }^{\prime}$-promoter region and a 1277 bp 3 '-untranslated region, in the northern Han Chinese population to further explore the relationship between $H T R 1 B$ and schizophrenia.

\section{Materials \\ Subjects}

Our sample comprised 310 schizophrenic patients (152 men and 158 women) and 313 genetically unrelated, healthy volunteers (153 men and 160 women), comprising a combined 623 individuals. All participants enrolled were of northern Han Chinese descent. Blood samples from schizophrenic patients were provided by the Third People's Hospital of Liaoning Province; those from healthy controls were supplied by the China Medical University's Forensic Evidence Department. Inclusion criteria included a diagnosis of schizophrenia by trained psychiatrists according to the Diagnostic and Statistical Manual of Mental Disorders, fourth edition (DSM-IV). Exclusion criteria included the presence of other psychiatric disorders. The results of patient questionnaires confirming no history nor present evidence of any psychiatric disorder and no history of mental disease for at least three prior generations were used to select healthy controls. All subjects provided written informed consent prior to enrollment in this study.

\section{SNP selection}

The following factors were considered for SNP selection: (1) as the function of the HTR1B coding region has been studied extensively, SNPs located within HTR1B regulatory regions were selected; (2) based on prior reports, we found that current knowledge of the association between schizophrenia and HTR1B polymorphisms in the Chinese Han population include the $5^{\prime}$ untranslated region (UTR), while the promoter and $3^{\prime}$ regulatory regions have not been well studied; and (3) according to the HTR1B polymorphism distribution, we selected SNPs with favorable polymorphisms (MAF $\geq 0.1)$. Considering that the regulatory effects of sequences that are distal to the coding region may be limited, we selected a 2285 bp 5 '-promoter region and a 1277 bp 3'-untranslated region for SNP investigation.

\section{DNA isolation and genotyping}

Genomic DNA was extracted by the phenol-chloroform method from whole blood [16]. A 2285 bp fragment in the 5 '-promoter region and a $1277 \mathrm{bp}$ fragment in the 3 '-untranslated region were included in our analysis. Standard PCR was performed in a total reaction volume of $20 \mu \mathrm{l}$ (adjusted with sterilized, deionized water) containing $2 \mu \mathrm{l}$ genomic DNA as template (approximately $50 \mathrm{ng}), 10 \mu \mathrm{l}$ of $2 \times \mathrm{GC}$ Buffer, $0.2 \mu \mathrm{l}(1 \mathrm{U})$ of Taq polymerase (Takara LA Taq, Dalian, China), $2 \mu \mathrm{l}(3.75 \mathrm{nmol})$ of dNTPs, $1.5 \mu \mathrm{l}(7.5 \mathrm{pmol})$ each of sense and antisense

Table 1 SNPs (14 total) detected in the northern Han Chinese population

\begin{tabular}{|c|c|c|c|c|}
\hline SNP & Chr. pos. & Base change $e^{1,2}$ & MAF & REGION \\
\hline rs4140535 & $77,465,335$ & $-1932 \mathrm{~T}>\mathrm{C}$ & 0.375 & 5'near gene \\
\hline rs1778258 & $77,464,492$ & $-1089 G>A$ & 0.113 & 5'near gene \\
\hline rs 17273700 & $77,464,263$ & $-860 \mathrm{~T}>\mathrm{C}$ & 0.121 & 5'near gene \\
\hline rs1228814 & $77,464,103$ & $-700 \mathrm{C}>\mathrm{A}$ & 0.166 & 5'near gene \\
\hline rs11568817 & $77,463,665$ & $-262 T>G$ & 0.116 & 5'UTR \\
\hline rs130058 & $77,463,564$ & $-161 \mathrm{~A}>\mathrm{T}$ & 0.077 & $5^{\prime} U T R$ \\
\hline rs6297 & $77,462,224$ & $* 7 A>G$ & 0.112 & 3'UTR \\
\hline rs3827804 & $77,462,215$ & $* 16 \mathrm{G}>\mathrm{A}$ & 0.011 & $3^{\prime} U T R$ \\
\hline rs140792648 & $77,462,065$ & ${ }^{*} 165$ - 166 Ins AG & 0.029 & 3'UTR \\
\hline rs9361234 & $77,461,965$ & ${ }^{*} 266 C>T$ & 0.113 & $3^{\prime} \mathrm{UTR}$ \\
\hline rs183156887 & $77,461,962$ & ${ }^{*} 269$ C > A & 0.0064 & 3'UTR \\
\hline rs76194807 & $77,461,898$ & $* 333 \mathrm{G}>\mathrm{T}$ & 0.113 & $3^{\prime} U T R$ \\
\hline rs58138557 & $77,461,771$ & $\begin{array}{l}{ }^{*} 459{ }^{*} 460 \\
\text { Del GG }\end{array}$ & 0.115 & 3'UTR \\
\hline rs13212041 & $77,461,407$ & ${ }^{*} 824 A>G$ & 0.256 & 3'UTR \\
\hline
\end{tabular}

${ }^{1}$ The A of the ATG start codon is designated as position 0

${ }^{2} \mathrm{An}$ asterisk (*) indicates alterations in the coding region, which is $1173 \mathrm{bp}$ in length 
Xia et al. BMC Psychiatry (2018) 18:303

Page 3 of 11

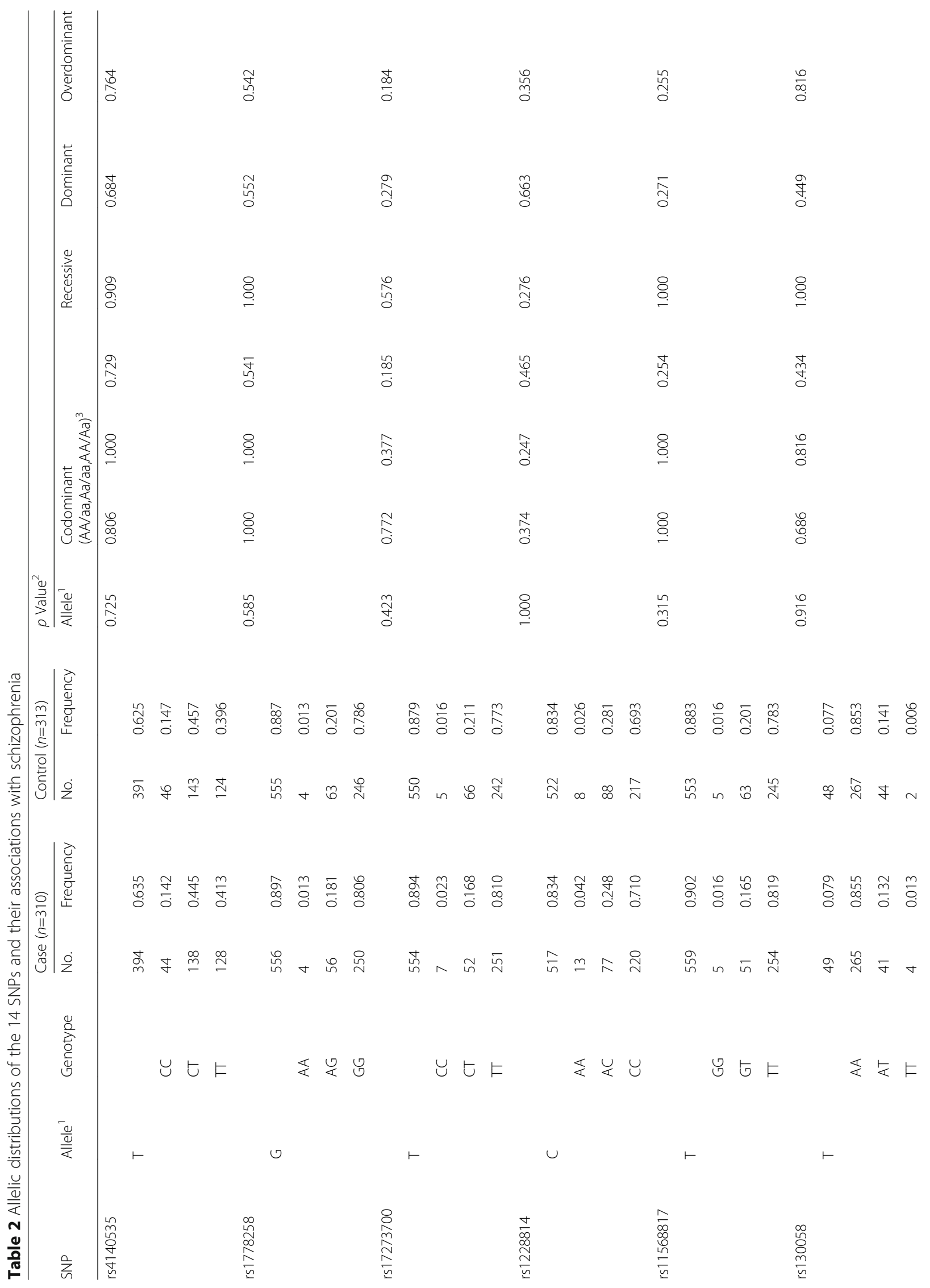


Xia et al. BMC Psychiatry (2018) 18:303

Page 4 of 11

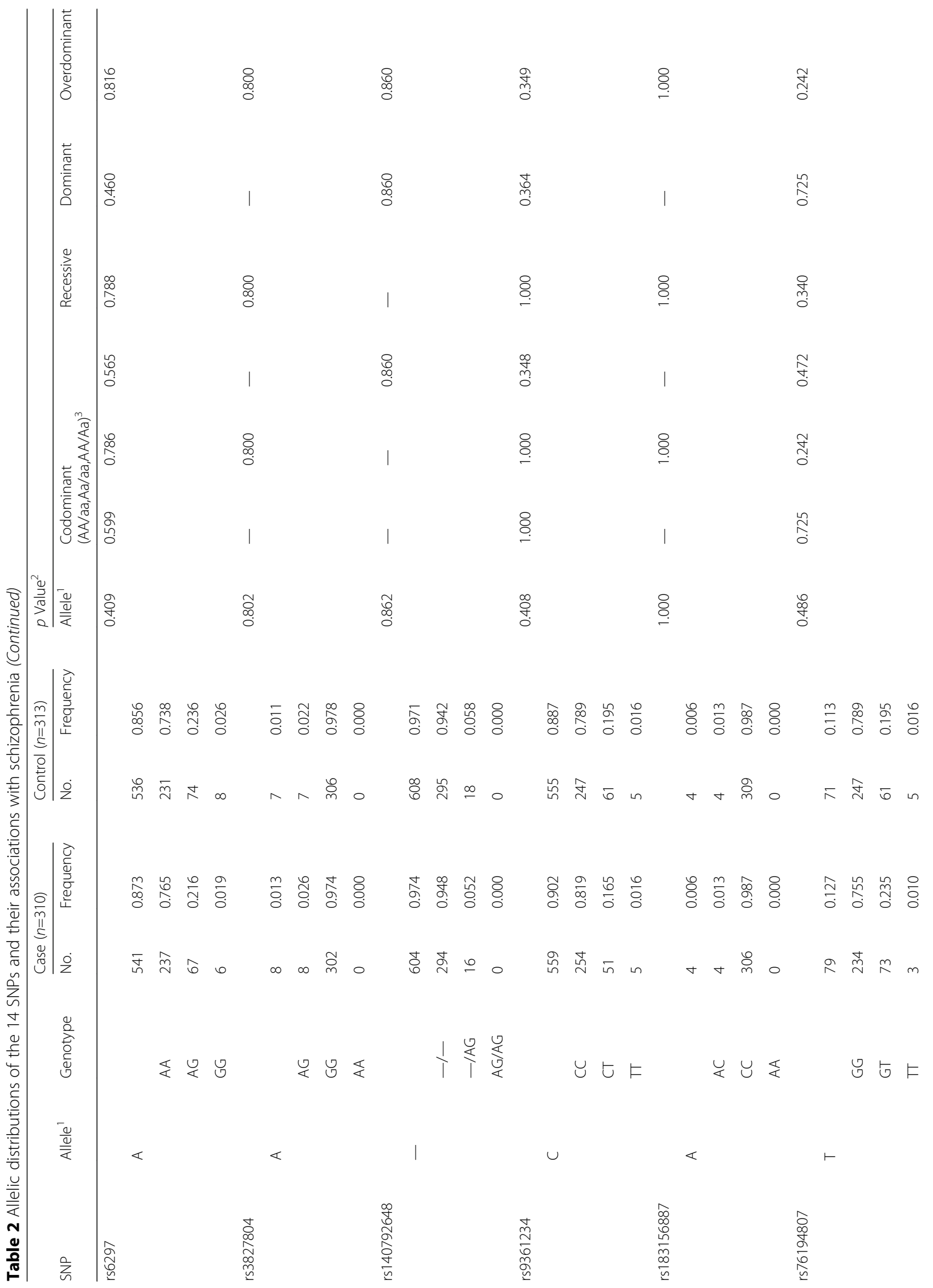


Xia et al. BMC Psychiatry (2018) 18:303

Page 5 of 11

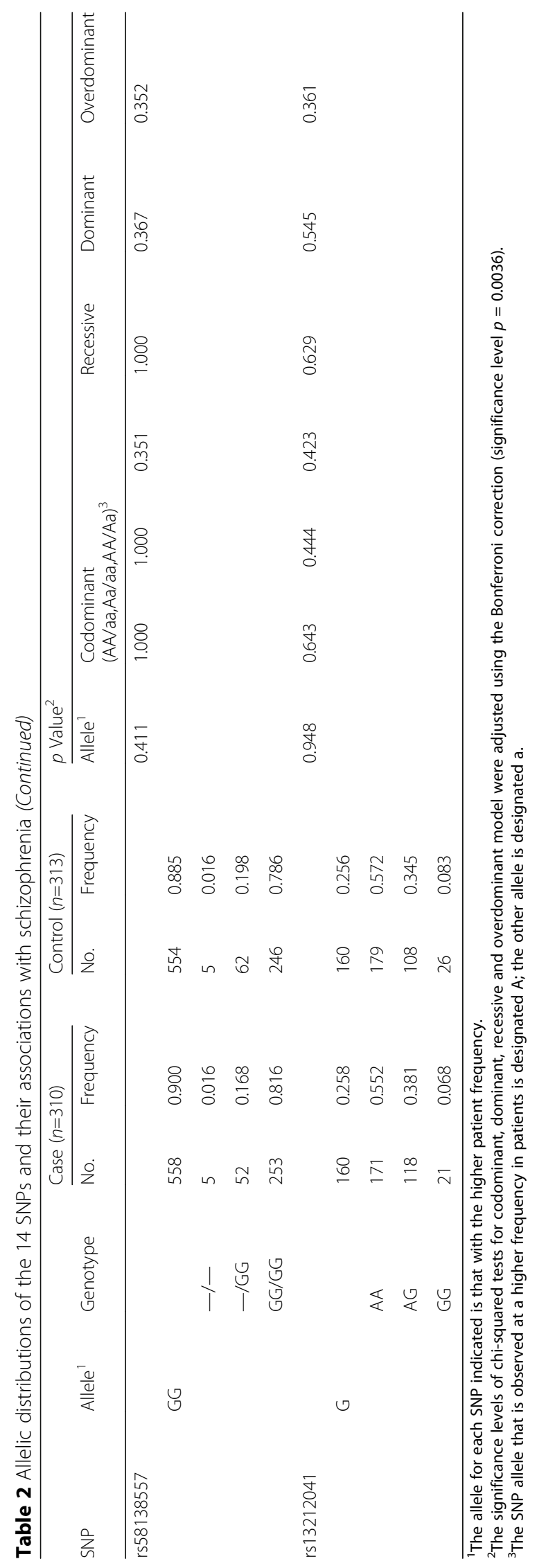


primers. The primer sequences of the $5^{\prime}$-end fragment were 5'-TGGGTTTGTGCTTTATTGCCTT-3' (sense), 5'-GGAGCAGAGGATAAGTTGGCTTG-3' (antisense), and the primer sequences of the $3^{\prime}$-end fragment were 5'-CCCTTCTTCATCATCTCCCTAGTG-3' (sense), 5'ACCCCATTCCTCAATTGTGTAAG-3' (antisense; Taihe Biotechnology Co., Beijing, China). PCR conditions for the $5^{\prime}$-end fragment were: $94{ }^{\circ} \mathrm{C}$ for $1 \mathrm{~min} ; 35$ cycles of $94{ }^{\circ} \mathrm{C}$ for $30 \mathrm{~s}, 58.4{ }^{\circ} \mathrm{C}$ for $30 \mathrm{~s}$, and $72{ }^{\circ} \mathrm{C}$ for $1.5 \mathrm{~min}$; then final extension at $72{ }^{\circ} \mathrm{C}$ for $7 \mathrm{~min}$. PCR conditions for the $3^{\prime}$-end fragment were $94{ }^{\circ} \mathrm{C}$ for $1 \mathrm{~min}$; by 35 cycles of $94{ }^{\circ} \mathrm{C}$ for $30 \mathrm{~s}, 60{ }^{\circ} \mathrm{C}$ for $30 \mathrm{~s}, 72{ }^{\circ} \mathrm{C}$ for $1 \mathrm{~min}$; and extension at $72^{\circ} \mathrm{Cfor} 7 \mathrm{~min}$. The Sanger double-chain termination method (Taihe Biotechnology Co., Beijing, China) was employed for DNA sequencing.

\section{Statistical analysis}

Allele and genotype frequencies were calculated by direct counting. Haplotype blocks were determined by the confidence interval method in Haploview. Using this method, six 5' -promoter region SNPs were included in a haplotype block, while the eight 3 '-promoter region SNPs were not included in a haplotype block. Thus, we performed analysis for haplotypes formed by the 6 SNPs in the block (namely, the $5^{\prime}$ block) and the remaining eight SNPs (designated the 3' block) [17].

In order to test Hardy-Weinberg equilibrium (HWE) and construct haplotype blocks, linkage equilibrium (LD) analysis ( $\mathrm{D}^{\prime}$ and $\mathrm{r}^{2}$ ) were performed using Haploview version 4.2 software (Broad Institute, Cambridge, MA, USA) [18]. The $\chi^{2}$ test was used to estimate correlations between the variance of polymorphism frequency distribution and schizophrenia. Statistical significance was defined as $p<0.05$ (two-tailed). Statistical analyses were performed using SPSS Software19.0 (IBM, Armonk, NY, USA). A Bonferroni correction was applied for multiple comparisons to control for type I error, and the $p$-value was divided by the total number of loci or haplotypes [17].

\section{Results}

We identified 14 SNPs in the present study (Table 1). The genotype distribution was in accordance with Hardy-Weinberg equilibrium in the control group. A summary of allele and genotype frequencies is presented in Table 2. We found that male patients were observed to have a significantly higher A-allele frequency at rs1778258 than female patients $(p=0.012)$. The frequency of A-allele carriers (AA+AG genotype) among male patients was also significantly higher than among female patients $(p=0.015)$, although statistical significance was lost after Bonferroni correction. The presence of both the $\mathrm{A}$-allele and $\mathrm{AA}+\mathrm{AG}$ genotype increased schizophrenia risk $(\mathrm{OR}=1.986$ and $\mathrm{OR}=2.061$, respectively; Table 3$)$.
Table 3 The relationship between rs1778258 and schizophrenia according to biological sex

\begin{tabular}{lllllll}
\hline Group & rs1778258 & Male & Female & $p$ value & OR & $95 \% \mathrm{Cl}$ \\
\hline case & A & $41 / 304$ & $23 / 316$ & 0.012 & 1.986 & $1.161-3.398$ \\
& AA+AG & $38 / 152$ & $22 / 158$ & 0.015 & 2.061 & $1.152-3.684$ \\
control & A & $33 / 306$ & $38 / 320$ & 0.706 & 0.897 & $0.547-1.472$ \\
& AA+AG & $38 / 153$ & $22 / 160$ & 0.891 & 0.945 & $0.550-1.622$ \\
\hline
\end{tabular}

${ }^{1} \mathrm{~A}$ significance level $p=0.05$

We found no significant associations between any other SNPs and schizophrenia.

Via linkage disequilibrium (LD) analysis, rs11568817 was found to be in strong linkage disequilibrium with rs17273700, rs9361234 and rs58138557 in northern Han Chinese patients $\left(r^{2}>0.8\right)$ [18]. We also found that, as compared to the healthy people, the linkage between rs11568817 and rs130058 in schizophrenic patients was more intense. Furthermore, LD analysis showed that the six 5' -promoter region SNPs are included in a haplotype using the confidence interval method, while the eight 3 '-promoter region SNPs were not included in a haplotype block (Fig. 1). We next compared the frequencies of haplotypes formed by the six SNPs in block or the remaining eight SNPs between the patients and healthy people, and found that the haplotype frequency distributions for the 5 '-promoter region C-G-C-A-G-A were significantly different among individuals in the case and control groups. $(p=0.044)$; however, statistical significance was lost after Bonferroni correction. No statistical differences between groups were observed for other haplotypes (Tables 4 and 5).

\section{Discussion}

In the present study, we investigated $H T R 1 B$ polymorphisms in 623 individuals of northern Han Chinese descent, including 310 schizophrenic patients and 313 healthy controls. We ultimately detected 14 SNPs. According to previously reported observations, no evidence regarding a relationship between $H T R 1 B$ and schizophrenia was found in any allele or major haplotype for T-261G, -182INS/DEL-181, A-161 T, C129T and G861C in Han Chinese patients [19]. Our study showed consistent results regarding rs11568817 (T-261G) and rs130058 (A-161 T). When patients were grouped by gender, male patients were observed to have a significantly higher frequency of A-allele at rs1778258 than female patients $(p$ $=0.012$ ). Based on multiple comparisons of genotype effects, we inferred that the most probable mode of inheritance of rs1778258 is the dominant model [20]. The frequency of the AA+AG genotype in male patients was also significantly higher than in female patients $(p=$ 0.015 ), although statistical significance was lost after Bonferroni correction. Both the A-allele and AA+AG 


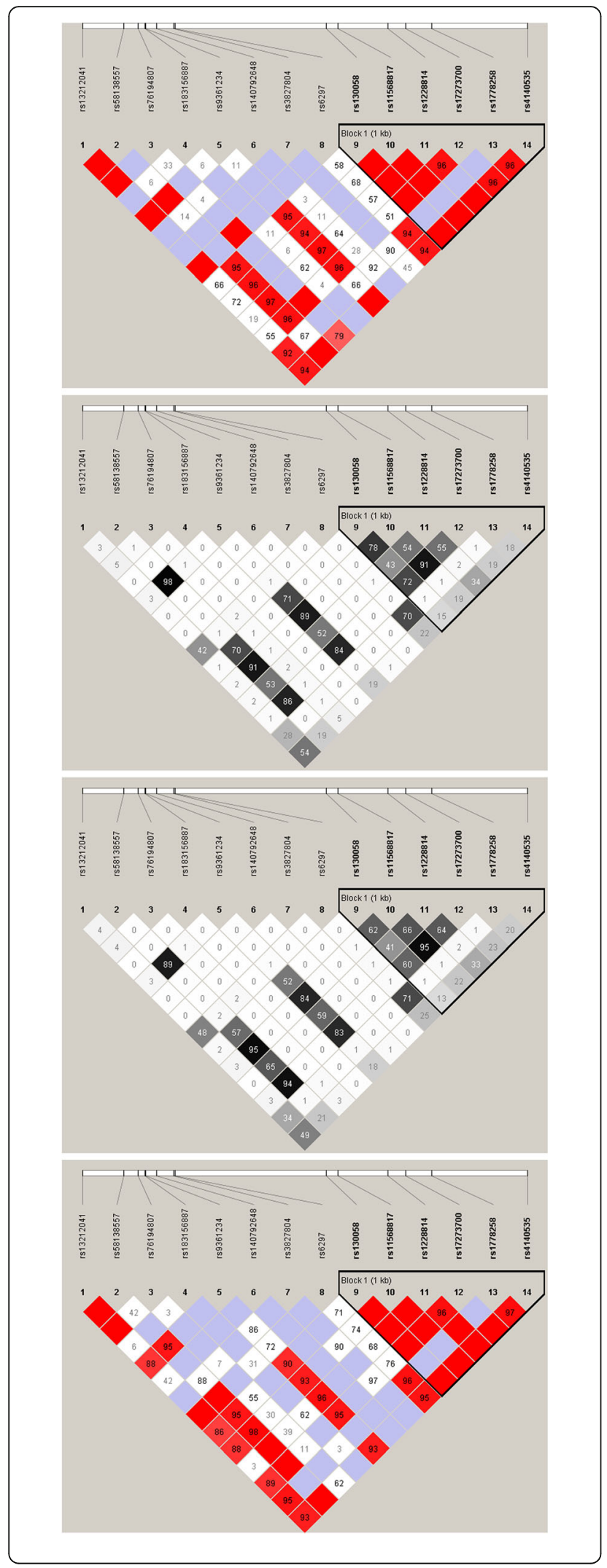

Fig. 1 Linkage disequilibrium diagram of the 14 SNPs in HTR1B in the northern Han Chinese population. Cases D'. Cases r r. Controls D'.

Controls $r^{2}$. The number in the grid of the red-white diagram represents the $D^{\prime}$ value, the deep red grid represents $D^{\prime} 1$, and the number in the grid of the black-white diagram represents the $r^{2}$ value

genotype were associated with increased risk of schizophrenia $(\mathrm{OR}=1.986$ and $\mathrm{OR}=2.061$, respectively). Thus, our study provides evidence that rs1778258 involved with gender variations in schizophrenia.

It is understood that sex differences exist in brain function as well as the vulnerability, incidence, manifestation, and treatment of numerous psychiatric diseases, which are determined by inherent biological differences between males and females. For instance, males show a higher propensity for Parkinson's disease, autism, attention deficit hyperactivity disorder (ADHD) and addiction. Females also show higher susceptibility to Alzheimer's disease and anxiety/depression [21]. Most studies have found the onset age of schizophrenia to be earlier in men than in women, although there is no sex difference in overall incidence of schizophrenia [22]. Men with schizophrenia also present with more cognitive disturbances and greater reductions in temporal lobe volume than women with schizophrenia [23]. Moreover, evidence also supports sex differences in serotonin neurotransmission and psychiatric disorders caused by malfunctions in the serotonin system. Such differences are not only due to hormonal regulation, but are also attributable genetic effects [21, 24]. It was previously reported that higher whole blood 5-HT levels in women than in men are influenced by multiple genes on chromosome 2, 6, and 17 [25]. In addition, the effects of sex hormones on serotonin regulation have also been reported. It has been shown that estradiol plays a protective role against the cognitive, positive, and negative symptom domains of schizophrenia [26]. Our results indicated that rs1778258 is associated with gender in schizophrenia. Since rs1778258 is located in the promoter region, it may have an influence on gene expression. Alternatively, there could be a functional site closely linked to rs 1778258 , and its variation thus could modify gene expression [27], which could have an influence on the serotonin system.

Previous genetic studies on schizophrenia have suggested that there is a gender-specific association between select dopamine genes and schizophrenia. Gender-specific associations between genotype and schizophrenia were also observed in GABAergic-mediated regulation of anterior cingulate cortex function. Male schizophrenic patients expressed significantly lower levels of $G A B A-A \alpha 5$, $G A B A-A \beta 1$, and $G A B A-A \varepsilon$, while the expression of $G A B A-A \beta 1$ and GAD67 was significantly higher in female patients, as compared to sex-matched controls [28]. Since 
Table 4 The relationship between 5'-region haplotype and schizophrenia

\begin{tabular}{|c|c|c|c|c|c|c|c|c|c|c|c|c|c|}
\hline \multicolumn{7}{|c|}{ Haplotype } & \multicolumn{2}{|c|}{ Case $(n=310)$} & \multicolumn{2}{|c|}{ Control $(n=313)$} & \multirow[b]{2}{*}{$p$ value $^{1}$} & \multirow[b]{2}{*}{ OR } & \multirow[b]{2}{*}{$95 \% \mathrm{Cl}$} \\
\hline$\overline{5^{\prime}}$ & rs4140535 & rs1778258 & rs17273700 & rs1228814 & rs11568817 & rs130058 & $\bar{N}$ & $\mathrm{~F}$ & $\overline{\mathrm{N}}$ & $\mathrm{F}$ & & & \\
\hline 1 & $\mathrm{~T}$ & G & $\mathrm{T}$ & $C$ & $\mathrm{~T}$ & A & 391.840 & 0.632 & 389.998 & 0.623 & 0.770 & 1.040 & $0.827-1.309$ \\
\hline 2 & $C$ & A & T & C & $\mathrm{T}$ & A & 62.620 & 0.101 & 70.112 & 0.112 & 0.583 & 0.898 & $0.627-1.288$ \\
\hline 3 & $C$ & G & $\mathrm{T}$ & $C$ & $\mathrm{~T}$ & A & 58.900 & 0.095 & 58.844 & 0.094 & 1.000 & 0.011 & $0.692-1.477$ \\
\hline 4 & C & G & C & A & G & T & 48.980 & 0.079 & 48.202 & 0.077 & 0.916 & 1.033 & $0.683-1.564$ \\
\hline 5 & $C$ & G & T & A & $\mathrm{T}$ & A & 39.060 & 0.063 & 30.048 & 0.048 & 0.266 & 1.334 & $0.817-2.176$ \\
\hline 6 & C & G & C & A & G & $A$ & 11.780 & 0.019 & 25.040 & 0.040 & 0.044 & 0.474 & $0.236-0.953$ \\
\hline
\end{tabular}

${ }^{1}$ Significance level $p=0.01$

it is known that these neurotransmitter systems are closely related [29], these differences may contribute to the gender-specific relationship between HTR1B polymorphisms and schizophrenia. Although sex differences are essential to study to fully understand the etiology of schizophrenia, unfortunately, few studies have been made regarding gender-specific associations between HTR1B and schizophrenia. The only association found to date was described in a Spanish population. The AAAC haplotype comprising rs6297, rs130058, rs1213366, and rs1213371 is significantly more frequent in female Spanish patients [15], which corroborates our finding that HTR1B genotype is related to gender in schizophrenia. It should be noted that rs1778258 was found to have a medium linkage with rs6297 $\left(r^{2}=0.7\right)$ in our study. However, both rs1778258 and rs6297 were found to lack any direct functional effects. Other SNPs had not been found to be associated with schizophrenia, but still provide references for HTR1B gene polymorphisms in the northern Han Chinese population.

This study found that the frequency distributions of haplotype C-G-C-A-G-A in the $5^{\prime}$-promoter region are significantly different between patients and healthy controls $(p=0.044)$, but statistical significance was lost after Bonferroni correction. It has been proposed that the rs11568817 G-allele and rs130058 T-allele influence gene expression by modifying the binding of transcription factors (TFs). The rs11568817 G-allele does enhance transcriptional activity; conversely, rs130058 T-allele can reverse this [30]. In our study, only haplotypes C-G-C-A-G-T and C-G-C-A-G-A contained functional sites rs11568817 G-allele or rs130058 T-allele, but no significant differences were found between patients and healthy controls in either haplotype after Bonferroni correction $(p=0.916$ and $p=0.044$, respectively. We also found that the $3^{\prime}$ region contains a known functional SNP, rs13212041. KP Jensen et al. confirmed that the rs13212041 A-allele can combine with microRNA (miR-96) to induce mRNA repression, and that this microRNA-mediated mRNA silencing could be attenuated by rs13212041 G-allele [31]. Conner et al. found that men with low expression haplotypes are inclined to present greater anger and hostility [27]. Although three known functional sites (rs11568817, rs130058, rs13212041) were found in our study, we discovered no direct associations between HTR1B and schizophrenia by haplotype. We hypothesize that the onset of schizophrenia could be affected by multiple functional sites, but their effects are counteracted [30]. Moreover, schizophrenia is associated with multiple neurotransmitters that have been noted to have physical and functional interactions [32]. Even these sites lead to changes in the serotonin system, but do not necessarily cause schizophrenia.

Our study showed that rs9361234, rs11568817 and rs17273700 are in strong linkage disequilibrium in the northern Han Chinese population. The linkage states of these SNPs are similar to those identified in Han Chinese populations in Beijing and southern China (1000 Genomes Project). We observed that rs58138557 was is intensely linked to rs9361234, rs11568817 and rs17273700 (Fig. 1). In addition, schizophrenic patients show stronger linkage between $11,568,817$ and rs130058 than healthy controls $\left(r^{2}=0.78\right.$ and $r^{2}=0.62$, respectively; Fig. 1). Linkage disequilibrium is related to population. For example, the linkage between rs11568817 and rs130058 in Han Chinese is weaker in northern China than in southern China based on the 1000 Genomes Project. This difference is also found in European and African-American populations [30]. Moreover, schizophrenia-associated genes vary among distinct ethnic populations [33]. Therefore, linkage disequilibrium of $H T R 1 B$ could be associated with schizophrenia in northern Han Chinese peoples. This study presents information on the linkage state of $H T R 1 B$ in schizophrenic patients of northern Han Chinese descent, and thereby provided references for the etiology of schizophrenia in different populations.

This study is limited by sample size and methods and, although we found that rs1778258 is related to gender in schizophrenia, unfortunately, the mechanism underlying this association was not addressed. This will require further exploration in the future. Because of the limitation of the candidate gene approach, caution must be taken in regards to the interpretation of the association we have observed. Since schizophrenia is a complex disease 


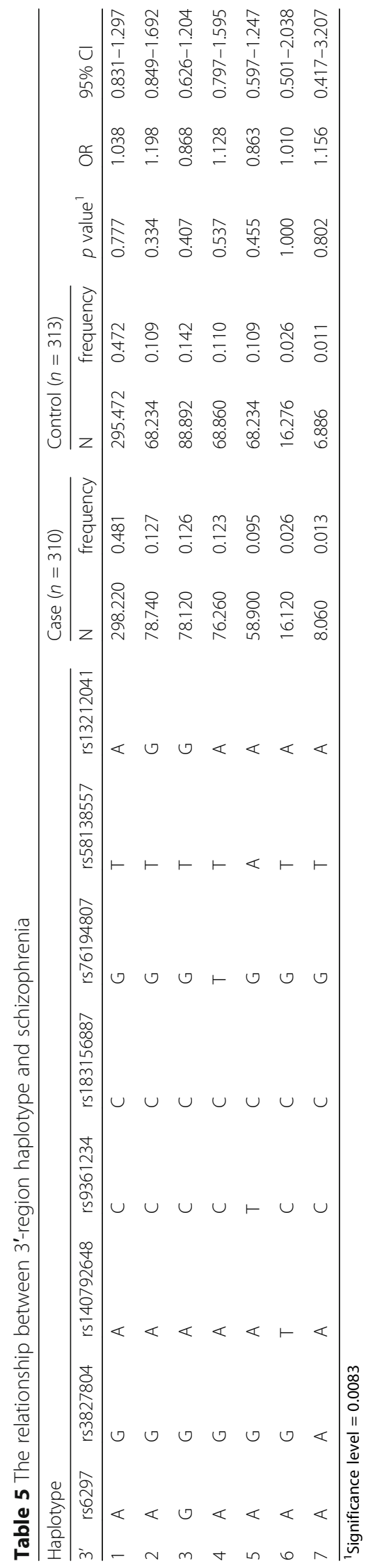


that is influenced by both genetic and environmental factors, both biological and psychological events experienced by individuals could have an impact on its onset. Thus, any associations cannot be fully explained by simply reducing them to a two-dimensional relationship between genetic variance and disease. We suggest that genetic background and behavioral events of enrolled patients should be taken into consideration [34]. Furthermore we will attempt to implement analysis of accurately defined phenotypes involving scale scores and treatment response, as well as the convergent analysis of genetic, serum and brain imaging markers.

\section{Conclusion}

In this study, the HTR $1 B$ gene was found to be related to gender in schizophrenia, as the rs1778258 A-allele caused increased risk of schizophrenia in male patients. Linkage between rs11568817 and rs130058 is more intense in schizophrenic patients. Combining all results of this study, we assert that HTR1B has a putative relationship with schizophrenia in the northern Han Chinese population, which provides a reference schizophrenia etiology.

\section{Abbreviations}

5-HT: 5-hydroxytryptamine; ADHD: Attention deficit hyperactivity disorder; DSM: Diagnostic Criteria of American Diagnostic and Statistical Manual of Mental Disorders; GWAS: Genome-wide association study; HTR1B: Serotonin receptor 1B; LD: Linkage disequilibrium; SNP: Single-nucleotide polymorphism; UTR: Untranslated region

\section{Acknowledgements}

We acknowledge all patients who participated in this study. We thank Xue Wu, Fengling Xu, Yi Liu, Yongping Liu, Xicen Zhang for assistance in many aspects of this work. The final version of the manuscript has been edited by the editors of BioMed Proofreading LLC.

\section{Funding}

Support has been provided by China Medical University. The funding body had no involvement with study design; data collection, analysis, or interpretation; or preparing the manuscript.

\section{Availability of data and materials}

The datasets used in this study are available from the corresponding author upon reasonable request.

\section{Authors' contributions}

BW conceived and designed this study. XX conducted the study, performed statistical analyses, and prepared the manuscript. JY revised the manuscript. $M D, J X 1, J X 2, H P$ played important roles in interpreting the results and providing relevant assistance in conducting study. All authors read and approved the final manuscript.

\section{Ethics approval and consent to participate}

The study was approved by the Ethics Committee of China Medical University. All subjects and/or patient guarantors provided written informed consent for participation in this study. This study was designed and performed according to the most recent version of the Declaration of Helsinki.

\section{Consent for publication}

Not applicable.

\section{Competing interests}

The authors declare that they have no competing interests.

\section{Publisher's Note}

Springer Nature remains neutral with regard to jurisdictional claims in published maps and institutional affiliations.

Received: 19 March 2018 Accepted: 13 August 2018

Published online: 19 September 2018

\section{References}

1. Sullivan PF, Kendler KS, Neale MC. Schizophrenia as a complex trait: evidence from a meta-analysis of twin studies. Arch Gen Psychiatry. 2003; 60(12):1187-92.

2. Liy-Salmeron G, Meneses A. Role of 5-HT1-7 receptors in short- and longterm memory for an autoshaping task: intrahippocampal manipulations. Brain Res. 2007;1147:140-7.

3. Barnes NM, Sharp T. A review of central $5-H T$ receptors and their function. Neuropharmacology. 1999;38(8):1083-152.

4. Guimaraes AP, Schmitz M, Polanczyk GV, Zeni C, Genro J, Roman T, Rohde $L A$, Hutz MH. Further evidence for the association between attention deficit/hyperactivity disorder and the serotonin receptor 1B gene. J Neural Transm. 2009:116(12):1675-80.

5. Moul C, Dobson-Stone C, Brennan J, Hawes DJ, Dadds MR. Serotonin 1B receptor gene (HTR1B) methylation as a risk factor for callous-unemotional traits in antisocial boys. PLoS One. 2015;10(5):e0126903.

6. Hakulinen C, Jokela M, Hintsanen M, Merjonen P, Pulkki-Raback L, Seppala I, Lyytikainen LP, Lehtimaki T, Kahonen M, Viikari J, et al. Serotonin receptor 1B genotype and hostility, anger and aggressive behavior through the lifespan: the young Finns study. J Behav Med. 2013;36(6):583-90.

7. Lopez-Figueroa AL, Norton CS, Lopez-Fiqueroa MO, Armellini-Dodel D, Burke S, Akil H, Lopez JF, Watson SJ. Serotonin 5-HT1A, 5-HT1B, and 5-HT2A receptor mRNA expression in subjects with major depression, bipolar disorder, and schizophrenia. Biol Psychiatry. 2004;55(3):225-33.

8. Veldman ER, Svedberg MM, Svenningsson P, Lundberg J. Distribution and levels of 5-HT1B receptors in anterior cingulate cortex of patients with bipolar disorder, major depressive disorder and schizophrenia - an autoradiography study. European neuropsychopharmacology : the journal of the European College of Neuropsychopharmacology. 2017;27(5):504-14.

9. Cao J, LaRocque E, Li D: Associations of the 5-hydroxytryptamine (serotonin) receptor $1 \mathrm{~B}$ gene (HTR1B) with alcohol, cocaine, and heroin abuse. American journal of medical genetics Part B, Neuropsychiatric genetics : the official publication of the International Society of Psychiatric Genetics 2013, 162B(2):169-176

10. Pal P, Mihanovic M, Molnar S, Xi H, Sun G, Guha S, Jeran N, Tomljenovic A, Malnar A, Missoni S, et al. Association of tagging single nucleotide polymorphisms on 8 candidate genes in dopaminergic pathway with schizophrenia in Croatian population. Croatian medical journal. 2009:50(4): 361-9.

11. Ambrosio AM, Kennedy JL, Macciardi F, Coelho I, Soares MJ, Oliveira CR, Pato CN. Lack of association or linkage disequilibrium between schizophrenia and polymorphisms in the 5-HT1Dalpha and 5-HT1Dbeta autoreceptor genes: family-based association study. American journal of medical genetics Part B, Neuropsychiatric genetics : the official publication of the International Society of Psychiatr Genet. 2004;128B(1):1-5.

12. Rujescu D, Giegling I, Sato T, Moller HJ. Lack of association between serotonin 5-HT1B receptor gene polymorphism and suicidal behavior. American journal of medical genetics Part B, Neuropsychiatric genetics : the official publication of the International Society of Psychiatric Genetics. 2003; 116B(1):69-71.

13. Cordeiro $\mathrm{Q}$, Vallada $\mathrm{H}$. Lack of association between the $\mathrm{G} 681 \mathrm{C}$ polimorphism in the 5-HT1D(beta) autoreceptor gene and schizophrenia. Arq Neuropsiquiatr. 2005;63(2B):380-2.

14. Sanders AR, Cao Q, Taylor J, Levin TE, Badner JA, Cravchik A, Comeron JM, Naruya S, Del Rosario A, Salvi DA, et al. Genetic diversity of the human serotonin receptor 1B (HTR1B) gene. Genomics. 2001;72(1):1-14.

15. Gilabert-Juan J, Ivorra JL, Tolosa A, Gratacos M, Costas J, Sanjuan J, Molto MD. Potential involvement of serotonin receptor genes with age of onset and gender in schizophrenia: a preliminary study in a Spanish sample. Psychiatry Res. 2011;186(1):153-4.

16. Kramvis A, Bukofzer S, Kew MC. Comparison of hepatitis B virus DNA extractions from serum by the QIAamp blood kit, GeneReleaser, and the phenol-chloroform method. J Clin Microbiol. 1996;34(11):2731-3. 
17. Zhu F, Yan CX, Wang Q, Zhu YS, Zhao Y, Huang J, Zhang HB, Gao CG, Li SB. An association study between dopamine D1 receptor gene polymorphisms and the risk of schizophrenia. Brain Res. 2011;1420:106-13.

18. Barrett JC, Fry B, Maller J, Daly MJ. Haploview: analysis and visualization of LD and haplotype maps. Bioinformatics. 2005;21(2):263-5.

19. Duan S, Yin H, Chen W, Xing Q, chen Q, Guo T, Gao J, Li X, Gao R, Liu Z, et al. No association between the serotonin $1 \mathrm{~B}$ receptor gene and schizophrenia in a case-control and family-based association study. Neurosci Lett. 2005;376(2):93-7.

20. Thakkinstian A, McElduff P, D'Este C, Duffy D, Attia J. A method for metaanalysis of molecular association studies. Stat Med. 2005;24(9):1291-306.

21. Ratnu VS, Emami MR, Bredy TW. Genetic and epigenetic factors underlying sex differences in the regulation of gene expression in the brain. J Neurosci Res. 2017:95(1-2):301-10.

22. Ochoa S, Usall J, Cobo J, Labad X, Kulkarni J. Gender differences in schizophrenia and first-episode psychosis: a comprehensive literature review. Schizophr Res Treat. 2012;2012:916198.

23. Bryant NL, Buchanan RW, Vladar K, Breier A, Rothman M. Gender differences in temporal lobe structures of patients with schizophrenia: a volumetric MRI study. Am J Psychiatry. 1999;156(4):603-9.

24. Gobinath AR, Choleris E, Galea LA. Sex, hormones, and genotype interact to influence psychiatric disease, treatment, and behavioral research. J Neurosci Res. 2017;95(1-2):50-64.

25. Weiss LA, Abney M, Cook EH Jr, Ober C. Sex-specific genetic architecture of whole blood serotonin levels. Am J Hum Genet. 2005;76(1):33-41.

26. Gogos A, Sbisa AM, Sun J, Gibbons A, Udawela M, Dean B. A role for estrogen in schizophrenia: clinical and preclinical findings. Int J Endocrinol. 2015;2015:615356.

27. Conner TS, Jensen KP, Tennen H, Furneaux HM, Kranzler HR, Covault J. Functional polymorphisms in the serotonin $1 \mathrm{~B}$ receptor gene (HTR1B) predict self-reported anger and hostility among young men. American journal of medical genetics Part B, Neuropsychiatric genetics : the official publication of the International Society of Psychiatr Genet. 2010;153B(1):67-78.

28. Li R, Ma X, Wang G, Yang J, Wang C. Why sex differences in schizophrenia? Journal of translational neuroscience. 2016;1(1):37-42.

29. Di Giovanni G, Esposito E, Di Matteo V. Role of serotonin in central dopamine dysfunction. CNS neuroscience \& therapeutics. 2010;16(3):179-94.

30. Duan J, Sanders AR, Molen JE, Martinolich L, Mowry BJ, Levinson DF, Crowe RR, Silverman JM, Gejman PV. Polymorphisms in the $5^{\prime}$-untranslated region of the human serotonin receptor 1B (HTR1B) gene affect gene expression. Mol Psychiatry. 2003:8(11):901-10.

31. Jensen KP, Covault J, Conner TS, Tennen H, Kranzler HR, Furneaux HM. A common polymorphism in serotonin receptor 1B mRNA moderates regulation by miR-96 and associates with aggressive human behaviors. Mol Psychiatry. 2009;14(4):381-9.

32. de Bartolomeis A, Buonaguro EF, lasevoli F. Serotonin-glutamate and serotonin-dopamine reciprocal interactions as putative molecular targets for novel antipsychotic treatments: from receptor heterodimers to postsynaptic scaffolding and effector proteins. Psychopharmacology. 2013;225(1):1-19.

33. Ohi K, Shimada T, Yasuyama T, Uehara T, Kawasaki Y. Variability of 128 schizophrenia-associated gene variants across distinct ethnic populations. Transl Psychiatry. 2017;7(1):e988.

34. Drago A, Alboni S, Brunello N, De Ronchi D, Serretti A. HTR1B as a risk profile maker in psychiatric disorders: a review through motivation and memory. Eur J Clin Pharmacol. 2010;66(1):5-27.

Ready to submit your research? Choose BMC and benefit from:

- fast, convenient online submission

- thorough peer review by experienced researchers in your field

- rapid publication on acceptance

- support for research data, including large and complex data types

- gold Open Access which fosters wider collaboration and increased citations

- maximum visibility for your research: over $100 \mathrm{M}$ website views per year

At $\mathrm{BMC}$, research is always in progress.

Learn more biomedcentral.com/submissions 